\title{
O SENTIDO POLÍTICO DA HISTÓRIA: CONSIDERAÇÕES SOBRE RAZÃO, LIBERDADE E ESTADO CONSTITUCIONAL EM KANT E HEGEL
}

\author{
Diogo Bogéa ${ }^{1}$ \\ Universidade do Estado do Rio de Janeiro (UERJ) \\ (D) https://orcid.org/0000-0001-5862-819X
}

\begin{abstract}
RESUMO:
No presente artigo investigaremos o sentido político da história na Filosofia da História de Kant e Hegel. Ambos atribuem, cada um à sua maneira, à concretização de um determinado projeto político - cujo cerne é a estruturação do Estado Constitucional - a realização da finalidade suprema da história humana. Analisaremos, para este fim, as obras Ideia de uma história universal de um ponto de vista cosmopolita, escrita por Kant em 1784, cinco anos antes da Revolução Francesa e A Razão na História - uma introdução geral à Filosofia da História, obra organizada a partir dos cursos proferidos por Hegel em sua maturidade. Nas considerações finais, procuraremos problematizar as noções de "sentido" e "finalidade" da História.
\end{abstract}

PALAVRAS-CHAVE: História; Política; Razão; Estado.

\section{THE POLITICAL MEANING OF HISTORY: CONSIDERATIONS ON REASON, FREEDOM AND THE CONSTITUTIONAL STATE IN KANT AND HEGEL}

\footnotetext{
ABSTRACT:

In this paper, we will investigate the political meaning of history in Kant's and Hegel's Philosophy of History. Both of them, each in its own way, the substantiation of a given political system - centered in the structuration of the Constitutional State - the fulfillment of human's history supreme

${ }^{1}$ Doutor em Filosofia pela Pontifícia Universidade Católica do Rio de Janeiro (PUC-Rio), Brasil. Professor Assistente de Filosofia Política da Educação na Universidade do Estado do Rio de Janeiro (UERJ), Brasil. E-mail: diogobogeaa@ hotmail.com

O sentido político da história: considerações sobre razão, liberdade e estado constitucional em Kant e Hegel Diogo Bogéa

Griot : Revista de Filosofia, Amargosa, Bahia - Brasil, v.15, n.1, p.376-390, junho/2017 
finality. We will analyze, to this end, the works Idea for a Universal History with a Cosmopolitan Purpose, written in 1784, five years before the French Revolution and Reason in History - a general introduction to Philosophy of History, organized from the lectures given by Hegel in his maturity. In the final considerations, we'll try to problematize the notions of "sense" and "finality" of History.

KEYWORDS: History; Politics; Reason; State.

\title{
Introdução
}

São bem conhecidas as implicações epistemológicas da filosofia de Kant. Sua "revolução copernicana" no conhecimento estabelece as formas puras da intuição sensível - tempo e espaço (KANT, 1974, p. 40) - e os conceitos puros do entendimento, ou categorias - de quantidade, qualidade, relação ou modalidade (KANT, 1974, p. 71) -, como elementos a priori, constitutivos do sujeito, os quais determinam a maneira como os objetos aparecem para nós. No entanto, nem sempre temos bastante clareza quanto ao sentido eminentemente político do projeto crítico kantiano. Sentido eminentemente político que se revela com clareza em sua Filosofia da História.

A obra Ideia de uma história universal de um ponto de vista cosmopolita, publicada em 1884, cinco anos antes da Revolução Francesa, introduz a reflexão kantiana acerca do "sentido da história". Recorreremos a esta obra para compreender em que medida Kant, ao atribuir um sentido político para a história, fazendo de um determinado projeto político a finalidade suprema da história humana, confere também um sentido político ao seu próprio sistema filosófico.

Iluminista, Kant estava imerso na "Weltanschauung" de seu tempo. Partilhava com seus companheiros de século a crença, até certo ponto justificada, de que

\begin{abstract}
A história humana era um avanço mais que um retrocesso ou um movimento oscilante ao redor de certo nível. Podiam observar que o conhecimento científico e o controle técnico do homem sobre a natureza aumentavam diariamente. Acreditavam que a sociedade humana e o homem individualmente podiam ser aperfeiçoados pela mesma aplicação da razão, e que estavam destinados a seu aperfeiçoamento na História. (HOBSBAWM, 2014, p. 164).
\end{abstract}

A razão se revelava como poder ativo (CASSIRER, 1992, p. 32), como "energia" capaz de libertar o espírito "de todos os fatos simples, de todos os dados simples, de todas as crenças baseadas no testemunho da revelação, da tradição, da autoridade" (CASSIRER, 1992, p. 32). Poder destruidor de todas as amarras espirituais herdadas da tradição e da 
autoridade, a razão "só descansa depois que desmontou peça por peça, até seus últimos elementos e seus últimos motivos, a crença e a 'verdade préfabricada" (CASSIRER, 1992, pp. 32-33). Mas a razão iluminista não se contenta com a destruição das tradições, das crenças injustificadas e do obscurantismo. Ela encarna também o poder criador que assume para si a responsabilidade de reconstruir sobre os escombros do passado uma nova imagem do mundo físico, um novo humano e uma nova sociedade - um novo humano, livre e racional e, portanto, capaz de construir uma sociedade mais justa e igualitária. Uma nova sociedade, construída sobre bases racionais e, portanto, capaz de formar um novo humano livre e racional. A razão

\begin{abstract}
Deverá construir um novo edifício, uma verdadeira totalidade. Mas ao criar ela própria essa totalidade, ao levar as partes ao constituírem o todo segundo a regra que ela própria promulgou, a razão assegura-se de um perfeito conhecimento da estrutura do edifício assim erigido. Ela compreende essa estrutura porque pode reproduzir-lhe a construção em sua totalidade e no encadeamento de seus momentos sucessivos. É mediante esse duplo movimento intelectual [destruição e criação] que a ideia de razão se concretiza plenamente: não como a ideia de um ser, mas como a de um fazer. (CASSIRER, 1992, p. 33)
\end{abstract}

Hegel escreve sua obra num outro momento. A Revolução Francesa, já realizada, concretiza as aspirações de liberdade e de racionalização da estrutura social, mas também revela os perigos dos seus excessos na fase do terror. Napoleão, que tanto encantou Hegel, com um golpe e sucessivas campanhas militares, consolidou na França um Estado forte, com uma sólida estrutura burocrática, que se tornará modelo para toda a Europa.

Na França, o povo, deliberadamente, se constitui como nação, mata seu rei - e, matando-o, realiza o holocausto instaura a República. Na Inglaterra, a máquina industrial, posta em movimento há alguns decênios, acelera-se e impõe efetivamente ao homem uma nova imagem da sua atividade; na Alemanha, na Itália, o tormento da unidade nacional deixa de ser um sonho e começa a tornar-se uma reivindicação que os fatos legitimam.

Logo a paranoia napoleônica lança sobre esses movimentos explosivos ou subterrâneos sempre dispares, sua luz ofuscante: o Estado, com sua administração, polícia, exército, poderes de controle e centralização, ergue-se como referência última. O êxito da organização napoleônica é tal que é preciso, caso se queira fazer oposição a ela eficazmente, imitá-la de alguma maneira. Mais que o Reino Unido, protegido por sua insularidade, a Prússia, depois de lena, cede à tentação. (CHATELET, 1995, p. 10) 
Os idealistas alemães, Hegel inclusive, como nos diz Marcuse em Razão e Revolução: "em grande parte, escreveram suas filosofias em resposta ao desafio vindo da França à reorganização do estado e da sociedade em bases racionais, de modo que as instituições sociais e políticas se ajustassem à liberdade e aos interesses do indivíduo." (MARCUSE, 1969, p. 15)

\begin{abstract}
A Revolução Francesa, aos olhos dos idealistas alemães, não só abolira o absolutismo feudal, substituindo-o pelo sistema econômico e político da classe média, mas, ao emancipar o indivíduo como senhor auto-confiante de sua vida, completara o que a Reforma Alemã havia começado. A situação do homem no mundo, seu trabalho e lazer, deveriam, doravante, depender de sua própria atividade racional livre e não de qualquer autoridade externa. $\mathrm{O}$ homem superara o longo período de imaturidade, durante o qual fora oprimido por esmagadoras forças naturais e sociais, e se tornara o sujeito autônomo de seu próprio desenvolvimento. Daí em diante, a luta contra a natureza e contra a organização social deveria ser orientada por seu próprio progresso no conhecimento. O mundo deveria tornar-se uma ordem de razão. (MARCUSE, 1969, pp. 15-16)
\end{abstract}

Partindo dessas considerações iniciais, nos colocamos em condições de compreender o contexto de produção da Filosofia da História de Kant e Hegel, contexto que determina seu forte sentido político.

\title{
Kant
}

Uma das questões que mais inquietou a modernidade foi a compreensão do humano como um estranho ente híbrido, que habita tanto o mundo material - e, portanto, está submetido ao reino da causa eficiente regido pelas leis da mecânica -, por outro lado, habita também o mundo "espiritual", isto é, enquanto ser racional deve ser livre para determinar sua própria vontade e agir de acordo com finalidades não determinadas pela ordem causal mecânica. Esta contradição humana essencial constitui a terceira antinomia da Dialética transcendental. Francesco Pecorari em seu artigo $O$ conceito de liberdade em Kant, expõe o problema:

Kant vai solucionar esta antinomia recorrendo à sua clássica e fundamental distinção entre "fenômeno" e "coisa em si" (nôumeno). Esta distinção lhe permite de introduzir dois tipos de causalidade: a "inteligível" e a "sensível". A primeira se refere à ação da "coisa em si" e a segunda à ação do "fenômeno". As duas podem causar o mesmo efeito ao mesmo tempo, assim o efeito produzido virá a ter uma dupla causalidade, ou, como diz Kant, um duplo "caráter": o "sensível", enquanto observável e segundo as leis da natureza, 
e o "inteligível", enquanto supra-sensível, quer dizer livre e segundo a espontaneidade do agente. Evidentemente, Kant está pensando na possibilidade de um sujeito capaz de produzir ações concretas determinadas contemporaneamente pelas duas causalidades: do ponto de vista fenomenal ou "caráter empírico" (sensível), sua ação é necessária, segue as leis constantes da natureza num encadeamento causal como todos os outros fenômenos; mas de outro lado, do ponto de vista "nouménico" ou "caráter inteligível", a mesma ação é fruto da espontaneidade de um sujeito capaz de auto-determinar-se e, como tal, independe de todas as condições da sensibilidade (espaço e tempo). Por enquanto, não podemos dizer quem é e como age essa causa "inteligível", pois é uma "coisa em si". (PECORARI, 2010, pp. 47-48)

Com a palavra caráter, "Kant entende a lei ou o motivo da ação. Escreve ele: 'Toute cause eficiente doit avoir un caractère, c'est-a-dire une loi de sa causalité, sans laquelle elle ne serait nullement cause"' (PECORARI, 2010, p. 53) (Toda causa eficiente deve ter um caráter, quer dizer, uma lei de sua causalidade, sem a qual ela não será de maneira alguma uma causa).

Hélio José dos Santos e Souza nos ajuda a compreender como funciona esta hibridez do agir humano:

Mundos distintos são regulados por princípios distintos, e na medida em que o homem é, ao mesmo tempo, membro participante tanto do mundo sensível quanto do mundo inteligível, a vontade dele parece estar sujeita a dois tipos de legislação. Do sujeito considerado membro do mundo sensível emana, de seu Eu empírico, o princípio egoísta, formado a partir do modo como a subjetividade de cada espectador é afetada pelos fenômenos do mundo e, portanto, válido apenas para a vontade de cada sujeito.

Ao mesmo tempo, enquanto membro do mundo inteligível, terá de levar em conta que de seu Eu puro emerge um princípio formal que, por estar fundado na razão, tem de valer para a vontade de todo ente racional. A razão demonstra, desse modo, sua atividade ao fornecer ao homem um princípio oriundo de suas próprias forças, diferentemente da sensibilidade que demonstra sua passividade ao necessitar do mundo empírico na formação de um princípio prático. (SOUZA, 2009, pp. 38-39)

Segundo seu "caráter empírico" o humano é determinado por um "conjunto de inclinações cuja principal característica é a insaciabilidade". O "caráter empírico" do humano é representado "pelo desejo sensível e a procura incessante pela satisfação das inclinações" (SOUZA, 2009, p. 45). A razão, enquanto atributo essencial universal do humano, deve estabelecer fins universais e não meramente particulares. Por isso as inclinações, via de regra, atuam contrariamente à razão, obstruindo seu bom funcionamento. 
Do "caráter inteligível" de nossas ações, no entanto, podemos deduzir que estabeleça fins universalmente válidos, mas não podemos efetivamente conhecê-lo, pois habita o domínio - insondável - da "coisa em si". Aguinaldo Pavão chama atenção para certos momentos da obra kantiana que parecem envolver o "caráter inteligível" das ações humanas no insondável. Em seu texto $O$ caráter insondável das ações morais em Kant encontramos uma bela e esclarecedora citação a esse respeito:

\begin{abstract}
A moralidade própria das ações (mérito e culpa), mesmo a de nosso próprio comportamento, permanece-nos totalmente oculta. As nossas responsabilidades só podem ser referidas ao caráter empírico. Mas quanto disto se deve imputar ao efeito puro da liberdade, quanto à simples natureza e quanto ao defeito de temperamento do qual não se é culpado, ou à natureza feliz (merito fortunae) do mesmo, eis algo que ninguém pode perscrutar e consequentemente, também não julgar (richten) com toda a justiça. (Kant, 1980b, p.279, n.; B 579, n. 80) (PAVÃO, 2007, p. 2)
\end{abstract}

Só podemos julgar as ações humanas com base em seu "caráter empírico", restando-nos inacessível seu "caráter inteligível", portanto, nunca podemos julgar - nem outras pessoas, nem "a nós mesmos" (PAVÃO, 2007, p. 2) - com plena justiça.

O próprio imperativo categórico, máxima expressão da lei moral racional, não nos fornece o conteúdo do "caráter inteligível" de nossas ações, nem de seus objetivos próprios - universalmente válidos. Ele não diz mais que: "Age apenas segundo uma máxima tal que possas ao mesmo tempo querer que ela se torne lei universal" (KANT, 2004, p. 59), isto é, agir na tentativa de uma máxima aproximação possível ao que poderia ser a despeito de permanecer insondável - o conteúdo fundamental do "caráter inteligível".

Em Ideia de uma História Universal de um ponto de vista cosmopolita, Kant se propõe a descortinar, tal como um cientista procede com relação à natureza, o "fio condutor" da história humana. Partindo por princípio de uma "doutrina teleológica da natureza", "todas as disposições naturais de uma criatura estão destinadas a um dia se desenvolver completamente e conforme um fim". "No humano", atenção ao parêntese de Kant: "(única criatura racional sobre a Terra)" "aquelas disposições naturais que estão voltadas para o uso de sua razão devem desenvolver-se completamente apenas na espécie e não no indivíduo" (KANT, 2011, p. 5), já que este dispõe apenas de um tempo limitado de existência, enquanto a espécie tem a capacidade de perpetuação. De modo que os "indivíduos" e "mesmo povos inteiros", "cada qual buscando seu próprio proveito", "seguem inadvertidamente, como a um fio condutor, o propósito da natureza, que lhes é desconhecido" (KANT, 2011, p. 4). 
Kant define "a razão" como "a faculdade de ampliar as regras e os propósitos do uso de todas as suas forças para muito além do instinto natural", a qual só pode "progredir aos poucos, de um grau de inteligência a outro" (KANT, 2011, pp. 5-6). A natureza deu ao humano "a razão e a liberdade da vontade que nela se funda". Sendo assim, não deve o humano "ser guiado pelo instinto, ou ser provido e ensinado pelo conhecimento inato", mas se vê obrigado a "tirar tudo de si mesmo". O que caracteriza essencialmente o humano não é o instinto ou alguma "ideia inata", mas tão somente a razão, bem como "a liberdade da vontade que nela se funda" (KANT, 2011, pp. 7-8).

No entanto, a razão e a liberdade só podem se desenvolver plenamente através de "uma constituição civil perfeitamente justa", a qual deverá ser então "a mais elevada tarefa da natureza para a espécie humana" (KANT, 2011, p. 10). Esta constituição política deverá ser tão justa internamente quanto externamente, isto é, nas relações entre Estados, chegando mesmo ao ponto em que haja um único Estado cosmopolita planetário. Kant conclui:

\footnotetext{
Pode-se considerar a história da espécie humana, em seu conjunto, como a realização de um plano oculto da natureza para estabelecer uma constituição política perfeita interiormente e, quanto a este fim, também exteriormente perfeita, como o único estado no qual a natureza pode desenvolver plenamente, na humanidade, todas as suas disposições (KANT, 2011, p. 17)
}

É somente no interior de uma constituição política perfeitamente justa, racionalmente organizada, ou seja, regida por leis estabelecidas unicamente pela razão, que o humano pode chegar a realizar sua plena liberdade, isto é, enquanto obedecendo às leis estabelecidas por aquele poder essencial que mais propriamente lhe caracteriza: o poder da razão. Realiza-se, portando, desta forma a "autonomia", a obediência às leis autoimpostas - porque impostas a cada um por aquilo que lhes caracteriza própria e essencialmente: a razão.

A "lei moral" nos impõe o dever de agir "como se" conhecêssemos as finalidades racionais do nosso agir: "como se nossas ações pudessem se converter em leis universais". Assim poderíamos dar nossa pequena contribuição à evolução humana, cuja história, apesar da aparente caoticidade das redes conflitantes de inclinações particulares, é secretamente guiada por uma razão astuciosa que conduz, num prazo muito longo para ser sequer compreendido nos estreitos limites de uma vida humana particular, nosso progresso evolutivo enquanto espécie. Para nos manter comprometidos com essa difícil tarefa, os "ideais regulativos" vêm nos incentivar a agir "como se" houvesse Deus, "como se" tivéssemos "livrearbítrio" e "como se" tivéssemos uma alma imortal (KANT, 2001, pp. 646- 
650). No Estado Constitucional nos aproximamos ao máximo do exercício de nossa auto-nomia, pois obedecemos a leis auto-impostas pela razão. Leis que, transcendendo o particular, aproximam-se da universalidade dos fins da razão.

Hegel

A realização de um Estado racionalmente organizado como sentido político da história humana encontra-se também presente numa das mais claras exposições da Filosofia da História de Hegel: A Razão na História. A Razão, "Verdadeiro Poder Eterno e Absoluto" (HEGEL, 2001, p. 52) é "a lei do mundo e, portanto, na história do mundo as coisas aconteceram racionalmente" (HEGEL, 2001, p. 53). A questão "de como a Razão é determinada em si e o que é a sua relação para com o mundo coincide com a questão: qual é o objetivo final do mundo? (HEGEL, 2001, p. 61) Bem, sendo a história o palco no qual ininterruptamente tem lugar a ação humana, trata-se, então, da dimensão do Espírito. O que caracteriza essencialmente o Espírito é a Liberdade. No entanto, esta auto-compreensão essencial lhe permanece velada, visto que em cada momento da história humana, enquanto dura o desenrolar de cenas históricas determinadas, têm-se a impressão - e uma impressão concretamente realizada - de que o Espírito é coagido a agir por forças que lhe são externas. $\mathrm{O}$ movimento da História é o desenvolvimento progressivo do autoconhecimento do Espírito, isto é, da progressiva ampliação da consciência de sua própria Liberdade. A história do mundo "representa o desenvolvimento da consciência de liberdade que tem o Espírito e a consequente realização dessa liberdade". "Este desenvolvimento implica um progresso gradual, uma série de diferenciações cada vez mais reais, resultantes da ideia de liberdade". (HEGEL, 2001, p. 115) "O essencial na história do mundo, vista de maneira geral, é a consciência da liberdade e a compreensão do desenvolvimento dessa consciência" (HEGEL, 2001, p. 117). Assim, A "Ideia de Liberdade" é "a essência do Espírito e o objetivo positivamente final da história". (HEGEL, 2001, p. 69)

As vontades e paixões individuais, atuando cada qual em proveito próprio, de maneira aparentemente caótica e despropositada, são secretamente conduzidas, na verdade, por uma "astúcia da razão - porque ela deixa as paixões trabalharem por si, enquanto aquilo através do qual ela se desenvolve [o indivíduo] paga o preço e sofre a perda" (HEGEL, 2001, p. 82).

Ao contemplar a história como sendo o cadafalso em que foram sacrificados a felicidade dos povos, a sabedoria dos Estados e a virtude dos indivíduos, necessariamente surge uma pergunta: para que princípio, a que objetivo final foram 
oferecidos estes sacrifícios monstruosos? (HEGEL, 2001, p. 67)

\title{
A resposta de Hegel:
}

\begin{abstract}
A Liberdade em si é o seu único objetivo e o propósito único do Espírito. Ela é a finalidade última para a qual toda a história do mundo sempre se voltou. Para este fim, todos os sacrifícios têm sido oferecidos no imenso altar da terra por toda a demorada passagem das eras. Só a Liberdade é a finalidade que se compreende claramente e se completa em si mesma, o único polo duradouro estável na mudança de acontecimentos e condições, o único princípio verdadeiramente eficaz que interpenetra o todo. Este objetivo final é o propósito de Deus para com o mundo. (HEGEL, 2001, p. 66)
\end{abstract}

Cada avanço na ampliação da consciência de Liberdade do Espírito corresponde a uma concretização efetiva. Os "imensos acúmulos de vontades, interesses e atividades constituem os instrumentos e meios para que o Espírito do Mundo atinja o seu objetivo, trazendo-o à consciência e percebendo o seu significado", o qual não é outro senão "a descoberta de si mesmo - a volta a si - e o contemplar-se na realidade concreta". (HEGEL, 2001, p. 71)

Essa concretização do Espírito, esta sua efetivação em "realidade concreta" corresponde à organização estatal: "O Estado é a ideia de Espírito na manifestação exterior da vontade humana e sua liberdade". (HEGEL, 2001, p. 98) A própria Liberdade é "o reconhecimento e a adoção de objetivos materiais universais como o Direito, a Lei e a produção de uma realidade que esteja em conformidade com elas: o Estado". (HEGEL, 2001, p. 111) Assim, chegamos à seguinte conclusão - análoga à conclusão de Kant:

O Estado se torna o objeto precioso da história do mundo; é onde a Liberdade obtém a sua objetividade e se mantém no gozo desta objetividade. A Lei é a objetividade do Espírito, é a vontade em sua forma verdadeira. Só a vontade que obedece à lei é livre, pois obedece a si e, estando em si, sendo independente, ela é livre. (...) quando a vontade subjetiva do humano se sujeita a leis, a contradição entre a liberdade e a necessidade desaparece. São necessários tanto o racional, como o material. Somos livres quando o reconhecemos como lei e o seguimos como sendo a matéria de nosso próprio ser. A vontade objetiva e a vontade subjetiva estarão conciliadas, então, formando um só conjunto harmonioso. (HEGEL, 2001, 91)

Se para Kant o Estado "dotado de uma constituição perfeitamente justa" é uma espécie de "ideal regulativo", "como uma tarefa infinita, jamais inteiramente realizada, porém sempre existente e insistente" (CHÂTELET, 
1990, p. 79), Hegel toma o Estado prussiano - no interior do qual desfruta de um grande prestígio acadêmico - como modelo de realização concreta do Espírito e de objetivação de sua Liberdade. Para Hegel, "a Alemanha federal, protestante, submetida à decisão - sempre contestada e contestável - do rei da Prussia (Frederico Guilherme III, lembremos), apresenta a imagem confusa do que poderia ser o Estado racional" (CHÂTELET, 1995, pp. 151-152). E ainda que, como afirma Châtelet, pela regra da Filosofia da História hegeliana, a Prússia esteja destinada a ser substituída por "alguma nação mais dinâmica", até que "na desordem das guerras, se instale o Estado universal":

Este, todavia, não será fundamentalmente diferente, em seu princípio, em seu modo de organização, em seu projeto, do i que encobre confusamente o Estado prussiano: haverá um monarca dotado de poder de decisão, um corpo de funcionários responsável por determinar o interesse geral, e "estados" representando os interesses particulares. (CHÂTELET, 1995, p. 153).

\section{Considerações finais}

Kant e Hegel apostam numa razão astuciosa capaz de guiar secretamente a história humana pelos trilhos de uma - nem sempre perceptível - linearidade progressiva, rumo a uma realização absoluta que viria na forma de um Estado perfeitamente organizado em bases racionais, no interior do qual se concretizariam enfim os ideais supremos de liberdade e justiça. Como aponta Karl Löwith, com muita propriedade, a Filosofia da História consiste numa

\footnotetext{
Interpretação sistemática da história universal de acordo com um princípio segundo o qual os acontecimentos e sucessões históricos se unificam e dirigem para um sentido final.

Considerada nesta acepção, a filosofia da história está, no entanto, na total dependência da teologia da história, em particular do conceito teológico da história como uma história de realização e de salvação. (LÖWITH, 1991, p. 15)
}

Em 1874, um ainda jovem professor Nietzsche, num ambiente acadêmico dominado pelo hegelianismo - revolucionário ou conservador -, faz uma dura crítica à intelligentsia alemã do período, mostrando já contar com a boa dose de acidez e ironia que o acompanharão até a última obra:

Para toda filosofia que acredita que um acontecimento político possa dissipar, ou ainda, resolver o problema da existência é uma brincadeira de filosofia, uma pseudofilosofia. Desde que o mundo existe, se viu frequentemente serem fundados Estados; esta é uma velha história. Como uma inovação política bastaria para fazer dos homens, de uma vez para sempre, os felizes 
habitantes da terra? Mas se alguém acredita verdadeiramente, com todo o seu coração, que isto é possível, que então o demonstre; pois, na verdade, ele merece se tornar professor de filosofia numa universidade alemã. (...)

Mas aqui experimentamos somente as consequências desta doutrina recentemente pregada em todos os lugares: que o Estado é o fim supremo da humanidade e que não há para o homem deveres mais elevados do que servir ao Estado; reconheço nisso, não uma recaída no paganismo, mas na estupidez. (NIETZSCHE, 2003, p. 165).

Para sermos justos com Kant e Hegel, o Estado, para eles, seria não exatamente a finalidade última da História, mas ainda um "meio" para a concretização de uma sociedade humana na qual se realizassem plenamente os ideais de justiça e liberdade. No entanto, ao operar uma conexão intrínseca entre a estrutura-meio - o Estado - e a finalidade suprema - a realização dos ideais de justiça e liberdade entre os humanos -, a Filosofia da História de Kant e Hegel acaba proporcionando uma identificação entre Estado e finalidade suprema da humanidade. A tal ponto que o Estado efetivamente estruturado acaba por apagar progressivamente seu caráter mediador na tarefa de promoção da liberdade e da justiça e passa a se apresentar como ideal já realizado. Ideal já realizado no interior do qual o indivíduo, como uma pequena engrenagem, deve se contentar em desempenhar sua tarefa a fim de manter funcionando a máquina burocrática que agora o engloba e o absorve. Assim, "paradoxalmente, a Revolução Francesa, que queria libertar os indivíduos, suscita uma organização mais racionalizada, isto é, de outro modo repressiva, da existência" (CHÂTELET, 1995, pp. 10-11).

Paradoxo de uma razão que paulatinamente perde seu caráter dinâmico, ativo - questionador, criativo e emancipatório - para se tornar fundamento estável de uma estrutura tecnocientífica controladora, de um progresso calculado de antemão e de um sentido pré-fabricado da existência humana.

\footnotetext{
A razão significa, de início, a nítida distinção entre factum e jus. De forma que essa distinção torna-se a arma principal contra a tradição (contra a pretensão do status quo de continuar a existir simplesmente porque ocorre que ele está aí) e prolonga-se na afirmação da possibilidade e do direito de os indivíduos e a coletividade encontrarem em si mesmos (ou produzirem) os princípios norteadores de suas vidas. Bem depressa, no entanto, a razão, processo aberto de crítica e de elucidação, transforma-se de um lado em computação mecânica e uniformizante (manifesta já durante a Revolução Francesa) e de outro lado em sistema universal e pretensamente exaustivo (pretensão claramente legível em Marx) (...)

A "Razão" - de fato, o entendimento -, apresenta-se então como fundamento auto-suficiente da atividade humana, ou
} 
linearmente (Kant, Condorcet, Comte, etc.) ou "dialeticamente" (Hegel, Marx). Resultado final: o capitalismo, o liberalismo e o movimento revolucionário clássico dividem o imaginário do progresso e a crença de que a potência materialtécnica como tal é a causa ou a condição decisiva da felicidade ou da emancipação humanas (imediatamente ou, após um prazo, num futuro desde já descontado. (CASTORIADIS, 1992, pp; 20-21).

A descrição de Castoriadis é precisa. Capitalismo, liberalismo e o movimento revolucionário clássico "dividem o imaginário do progresso". A lógica capitalista se apropria do Estado, a mão - nada invisível - dos grandes grupos empresariais e financeiros assumem o controle, tornando-o um meio para a realização de interesses econômicos privados, um meio para a multiplicação dos lucros de empresários, financistas e de uma "classe política" que, por seus auto legitimados privilégios políticos e econômicos, torna-se cada vez mais apartada da sociedade.

A lógica liberal, associada ao capitalismo, traz a promessa de felicidade "para cada um" que esteja disposto a se esforçar o bastante para atingir o objetivo único, comum, homogêneo: multiplicar lucros e acumular bens materiais. A linearidade progressiva e teleológica da Filosofia da História é miniaturizada e transposta para o âmbito da vida individual, enquanto a sociedade vive um eterno presente, já que supostamente o "fím da história" já está plenamente realizado no Estado democrático liberal. É o que expressa, por exemplo, a tese de Fukuyama, que, distorcendo a Filosofia da História de Hegel, faz o "fim da história" coincidir com o "Estado democrático liberal” já plenamente realizado. Segundo Fukuyama:

1) Hegel afirma que o fim da história é a liberdade; 2) só nas democracias liberais há liberdade; 3 ) o comunismo perdeu a guerra fria para as democracias liberais e isto prova que não existe nada superior a elas (democracias liberais); 4) temos democracias liberais por todo o mundo, logo temos liberdade, logo temos o "fim da história" previsto por Hegel. (SCALDAFERRO, 2009, p. 224).

E, por fim, o "movimento revolucionário clássico" segue apostando nas leis da História que, em algum ponto do futuro, realizarão enfim uma estrutura sociopolítica no interior da qual os ideais de justiça e liberdade serão enfim concretizados. Mas atribuir um "sentido" único, préestabelecido e inescapável para a história humana, traz o perigo de fazer do humano singular uma espécie de autômato a quem cabe tão somente assumir o papel pré-determinado que supostamente lhe cabe na trama da história universal. E traz um perigo ainda maior: se a história tem um sentido determinado, toda e qualquer violência que esteja de acordo com a noção de "progresso" estabelecida por esse sentido, torna-se automaticamente legítima e justificada. E isso não se restringe à suposta necessidade da 
"violência revolucionária", como observamos no comentário de Marx à invasão e colonização da Índia pela Inglaterra: "quaisquer que possam ter sido os crimes da Inglaterra, ela foi o instrumento inconsciente da história" (MARX, 1982, pág. 517-518), pois "destruiu" a "primitiva" civilização indiana, instalando em seu lugar as instituições burguesas que constituíam o estágio atual da história universal.

Promessas de realização absoluta, seja no progresso rumo a uma finalidade suprema ou na recuperação de uma idade de ouro perdida, promessas de felicidade e de um perfeito ordenamento da sociedade trazem consigo o germe do autoritarismo e estão sempre presentes nas falas dos "messias" - de terno, de vermelho ou em fardas militares - que se apresentam como "salvadores da pátria". Será possível resistir ao desejo e à fantasia de uma satisfação absoluta? Será possível ajustar nossas aspirações a uma realidade que, muito mais modesta que nossos sonhos, tende a nos parecer decepcionante? Ainda que a resposta seja negativa, será possível ao menos um "contra-ideal"? Em seu Schopenhauer Educador, após criticar aqueles que veem no "serviço do Estado seu dever supremo", Nietzsche nos lembra que existem "outros homens e outros deveres", e afirma que um desses deveres é para ele superior ao do serviço ao Estado: "destruir a estupidez sob todas as suas formas, incluída aí portanto aquela forma" (NIETZSCHE, 2003, p. 165). Seria esse um "ideal regulativo" mais lúcido do que aqueles vislumbrados pela razão especulativa kantiana? Talvez o exercício da filosofia, enquanto questionamento radical capaz de revelar o fundo falso, humano demasiado humano dos nossos ideais supremos, possa nos ajudar a experimentar diversas des-identificações em relação aos papeis pré-fabricados nos quais esses ideais - políticos, religiosos, culturais - não cessam de tentar nos enquadrar. Talvez essas des-identificações nos conduzam somente ao vazio, ao abismo, ao nada. Mas talvez seja justamente aí, diante do vazio, do abismo, do nada, que nos coloquemos em condições de ressignificar também nossas aspirações políticas. Talvez, mais importante do que saber para onde ir, mais importante do que conhecer o sentido e o destino da história, mais importante do que acreditar em mais uma promessa de salvação absoluta, seja deixar sobrevir o abalo da experiência de não saber, de não conhecer, de não acreditar. Restaria então o tatear no escuro, como na descrição de Derrida, de um cego que escreve:

O que é que se passa quando se escreve sem ver? uma mão de cego aventura-se solitária ou dissociada, num espaço mal delimitado, tateia, apalpa, acaricia tanto quanto inscreve, fia-se na memória dos fios e suplementa a vista, como se um olho sem pálpebra se abrisse na ponta dos dedos: o olho a mais acaba de brotar rente à unha, um único olho, um olho de zarolho ou de ciclope e dirige o traçado - é uma lâmpada de mineiro na ponta da escrita, um substituto curioso e vigilante, a prótese de um vidente ele mesmo invisível. Do movimento das letras, do que assim inscreve este olho no dedo, a imagem

O sentido político da história: considerações sobre razão, liberdade e estado constitucional em Kant e Hegel Diogo Bogéa 
esboça-se sem dúvida em mim. A partir do retraimento absoluto de um centro de comando invisível, um poder oculto assegura à distância uma espécie de sinergia que coordena as possibilidades de ver, de tocar e de mover. E de ouvir e entender, porque são já palavras de cego que eu assim desenho. (DERRIDA, 2010, p 11 e 12).

Fica por pensar em que medida uma política do "tatear no escuro" não seria mais lúcida do que a luminosidade absoluta de uma razão, de um sentido, de uma finalidade ou de uma promessa de realização suprema de qualquer espécie. 


\section{Referências bibliográficas}

CASSIRER, Ernst. A filosofia do Iluminismo. Campinas: Ed. UNICAMP, 1992

CASTORIADIS, Cornelius. Encruzilhadas do labirinto III. O mundo fragmentado. Rio de Janeiro: Paz e Terra, 1992

CHÂTELET, François. Hegel. Rio de Janeiro: Zahar, 1995

. História das Ideias Políticas. Rio de Janeiro: Zahar, 1990

DERRIDA, Jacques. Memórias de Cego: O auto-retrato e outras ruínas. Tradução: Fernanda Bernardo. Lisboa: Fundação Calouste Gulbenkian, 2010

HEGEL, G. W. F., Grundlinien der Philosophie des Rechts oder Naturrecht und Staatswissenschaft im Grundrisse, Vorrede, Werke, vol. 7, red. Eva Moldenhauer e Karl Markus Michel, Frankfurt am Main, Suhrkamp Verlag, 1995

. A Razão na História. São Paulo: Centauro, 2001

HOBSBAWM, Eric. A era das revoluções. Rio de Janeiro: Paz e Terra, 2014

KANT, Immanuel. Ideia de uma história universal de um ponto de vista cosmopolita. São Paulo: Martins Fontes, 2011

. Crítica da razão pura. Lisboa: Calouste Gulbenkian, 2001

. Crítica da Razão Pura. São Paulo: Abril Cultural, 1974

- Fundamentação da metafísica dos costumes. Lisboa: Edições 70, 2004

MARX, Karl. "A dominação britânica na Índia". / "Resultados futuros da dominação britânica na Índia”. In: MARX \& ENGELS. Obras escolhidas. Tomo I. Lisboa, Edições Avante! / Moscou, Edições Progresso, 1982.

NIETZSCHE, Friedrich. Schopenhauer Educador. In SOBRINHO, Noéli Correia de Melo (Tradução apresentação e notas). Escritos sobre educação. Rio de Janeiro: PUC-Rio, 2003

PECORARI, Francesco. O conceito de liberdade em Kant. Ética e Filosofia Política, n. 12, v.1, 2010, pp. 44-59

PAVÃO, Aguinaldo. O caráter insondável das ações morais em Kant. Trans/Form/Ação, São Paulo, 30(1), 2007, pp. 101-113

SCALDAFERRO, Maikon. Hegel e o fim da História. In Polymatheia, v. 5, n. 8, 2009, pp. 211-230

SOUZA, Hélio José dos Santos e. O problema da motivação moral em Kant. São Paulo: UNESP, 2009.

Autor(a) para correspondência: Diogo Bogéa, Universidade do Estado do Rio de Janeiro, R. São Francisco Xavier, 524, Maracanã, CEP 20550-900, Rio de Janeiro - RJ, Brasil. diogobogeaa@hotmail.com 